\title{
Donor polymer fluorination doubles the efficiency in non-fullerene organic photovoltaics $\uparrow$
}

\author{
Nicole Bauer, (D) a Qianqian Zhang, (D) a Jingshuai Zhu, ${ }^{\mathrm{b}}$ Zhengxing Peng, $^{\mathrm{c}}$ \\ Liang Yan, (DD ${ }^{a}$ Chenhui Zhu, ${ }^{d}$ Harald Ade, ${ }^{c}$ Xiaowei Zhan (D) ${ }^{b}$ and Wei You (DD *a
}

Donor polymer fluorination has proven to be an effective method to improve the power conversion efficiency of fullerene-based polymer solar cells (PSCs). However, this fluorine effect has not been wellstudied in systems containing new, non-fullerene acceptors (NFAs). Here, we investigate the impact of donor polymer fluorination in NFA-based solar cells by fabricating devices with either a fluorinated conjugated polymer (FTAZ) or its non-fluorinated counterpart (HTAZ) as the donor polymer and a small molecule NFA (ITIC) as the acceptor. We found that, similar to fullerene-based devices, fluorination leads to an increased open circuit voltage $\left(V_{\text {oc }}\right)$ from the lowered HOMO level and improved fill factor (FF) from the higher charge carrier mobility. More importantly, donor polymer fluorination in this NFA-based system also led to a large increase in short circuit current $\left(J_{s c}\right)$, which stems from the improved charge transport and extraction in the fluorinated device. This study demonstrates that fluorination is also advantageous in NFA-based PSCs and may improve performance to a higher extent than in fullerenebased PSCs. In the context of other recent reports on demonstrating higher photovoltaic device efficiencies with fluorinated materials, fluorination appears to be a valuable strategy in the design and synthesis of future donors and acceptors for PSCs.

Received 7th September 2017

Accepted 9th October 2017

DOI: $10.1039 / \mathrm{c} 7 \mathrm{ta} 07882 \mathrm{j}$

rsc.li/materials-a
0 to $100 \% \mathrm{~F}$ ) to further investigate the impact of fluorine in this system. ${ }^{7}$ The authors found that PCE increased as amount of fluorine increased, due mainly to an increase in FF. Through a comprehensive study of device properties, this increase in FF was attributed solely to an increase in hole mobility with increased fluorination. ${ }^{7}$

Recently, non-fullerene acceptors (NFAs) have become more popular as electron acceptors than traditional fullerene derivatives in PSCs. ${ }^{8-10}$ Compared with fullerene derivatives, NFAs benefit from improved light absorption and easier tuning of optoelectronic properties, allowing for complementary $\left(J_{\mathrm{sc}}\right)$, open circuit voltage $\left(V_{\mathrm{oc}}\right)$, and fill factor $(\mathrm{FF})$ of the solar cells, leading to an overall improvement in PCE from $4.3 \%$ to 7.1\% for HTAZ and FTAZ, respectively. Later, Li et al. optimized the molecular weight of FTAZ ${ }^{6}$ and designed a series of BnDT(X)TAZ polymers with varying amounts of fluorination (from

${ }^{a}$ Department of Chemistry, University of North Carolina at Chapel Hill, Chapel Hill, North Carolina 27599, USA. E-mail: wyou@unc.edu

${ }^{b}$ Department of Materials Science and Engineering, College of Engineering, Key Laboratory of Polymer Chemistry and Physics of Ministry Education, Peking University, Beijing 100871, China

'Department of Physics and ORaCEL, North Carolina State University, Raleigh, North Carolina 27695, USA

${ }^{d}$ Advanced Light Source, Lawrence Berkeley National Laboratory, Berkeley, California 94720, USA

$\dagger$ Electronic supplementary information (ESI) available. See DOI: 10.1039/c7ta07882j
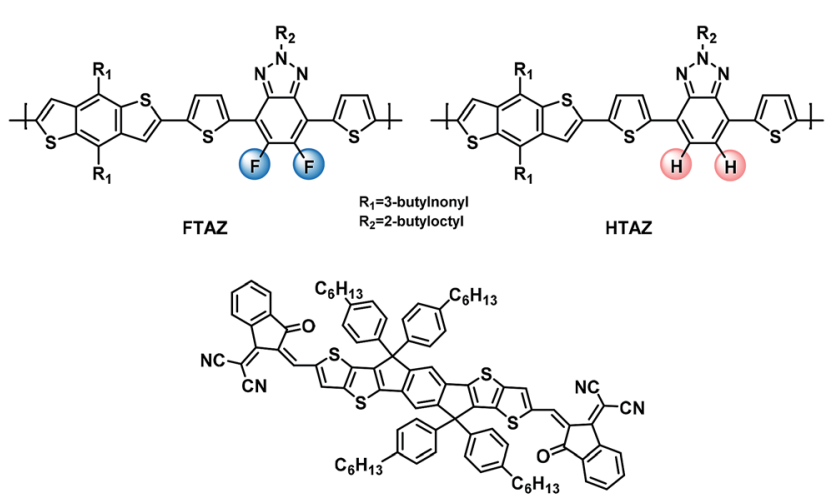

ITIC

Chart 1 Chemical structures of FTAZ, HTAZ, and ITIC. 
absorption and energy level matching with those of donor polymers to improve $J_{\text {sc }}$ and $V_{\text {oc }}$. Among all NFAs, ITIC (Chart 1) and its derivatives are the most studied and have shown great potential in advancing the efficiency of polymer solar cells. ITIC has an indacenodithieno[3,2- $b]$ thiophene core and 2-(3-oxo-2,3dihydroinden-1-ylidene)malononitrile end groups, and was first introduced as a NFA by Lin et al. in 2015. ${ }^{11}$ When ITIC was paired with PTB7-Th, a popular donor polymer, in BHJ solar cells, a PCE of $6.80 \%$ was obtained, which was the highest efficiency for NFA-based devices at that time. Since then, ITIC and its derivatives have become commonly used acceptor molecules to reach higher PCEs for PSCs. ${ }^{12-23}$ Just recently, Zhao et al. found that fluorination of the acceptor molecule can also lead to improved PSC performance. They designed a fluorinated ITIC derivative which, when paired with the FTAZ polymer, achieved a PCE of $13.1 \%$, the highest reported efficiency for PSCs to date. ${ }^{\mathbf{2 4}}$

While there are a few reports of donor polymer fluorination improving efficiency in NFA-based solar cells, ${ }^{25,26}$ the majority of work on the so-called "F effect" has been focused on fullerene-based systems (e.g., PCBM, phenyl- $\mathrm{C}_{61}$-butyric acid methyl ester). In this study, we aim to investigate the impact of donor polymer fluorination in these NFA-based systems, and determine if fluorination has a positive effect on device performance similar to that in fullerene-based devices. To accomplish this, we have fabricated $\mathrm{BHJ}$ devices with either non-fluorinated TAZ (i.e., HTAZ) or its fluorinated version (i.e., FTAZ) as the donor polymer and ITIC as the nonfullerene acceptor, as FTAZ has proven to be a good match for ITIC and its derivatives in previous reports. ${ }^{12,15}$ By studying the photovoltaic and morphological properties of the FTAZ:ITIC and HTAZ:ITIC devices, we found that fluorination also led to an increased PCE in this NFA-based system due in part to an improved $V_{\text {oc }}$ and FF. This result is similar to these polymers with PCBM; ${ }^{5}$ however, unlike the PCBM-based devices, the increase in efficiency for the ITIC-based devices was also in large part due to an increase in $J_{\mathrm{sc}}$ with fluorination.

\section{Results and discussion}

\section{Optical and electrochemical properties}

We first considered the optical and electronic properties of FTAZ, HTAZ, and ITIC. As displayed in Fig. 1a, the absorption of both FTAZ and HTAZ is complementary to that of ITIC, which would allow for an improved $J_{\text {sc }}$ compared to fullerene-based devices with these polymers. The highest occupied molecular orbital (HOMO) levels of the materials were measured via cyclic voltammetry (Fig. S1†), and the lowest unoccupied molecular orbital (LUMO) levels were calculated using the HOMO level and absorption onset from UV-Vis spectra. The HOMO and LUMO levels of the materials are displayed in Fig. 1b. As expected, the HOMO level of FTAZ is lowered compared to that of HTAZ, due to the electron-withdrawing nature of the fluorine substituents, which would lead to an increase in $V_{\text {oc }}$ for the FTAZ-based photovoltaic devices.
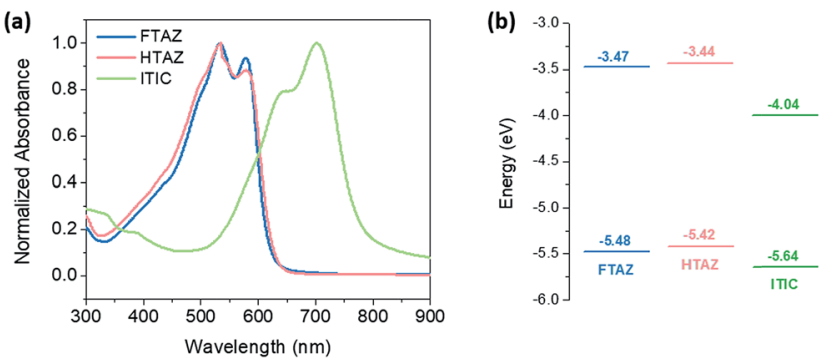

Fig. 1 (a) Normalized absorption and (b) energy levels of FTAZ, HTAZ, and ITIC.

\section{Device performance}

To determine the effect of fluorination on photovoltaic performance, bulk heterojunction devices were prepared with a device structure of ITO/ZnO/polymer:ITIC/ $\mathrm{MoO}_{3} / \mathrm{Al}$, a polymer : ITIC ratio of $1: 1.5$ and an active layer thickness of $\sim 90 \mathrm{~nm}$. The photovoltaic characteristics are given in Table 1 , with representative $J-V$ curves displayed in Fig. 2a. As expected, addition of fluorine substituents led to an increase in $V_{\text {oc }}$ due to the lower HOMO level of FTAZ, as $V_{\text {oc }}$ is largely correlated to the difference between the HOMO level of the donor and LUMO of the acceptor. Fluorination also led to a $40 \%$ improvement in FF, which is similar to that observed in the fullerene-based devices for these polymers. ${ }^{5}$ Additionally, the FTAZ:ITIC device also displayed a large increase in $J_{\mathrm{sc}}$, with a $J_{\mathrm{sc}} 30 \%$ higher than that of the HTAZ:ITIC device. Notably, this improvement in $J_{\mathrm{sc}}$ has not been observed in previously published studies of PCBMbased devices with these TAZ polymers. Overall, the power conversion efficiency of FTAZ:ITIC (8.37\%) was nearly double that of HTAZ:ITIC (4.26\%), due mainly to the increase in both $J_{\mathrm{sc}}$ and FF. This efficiency of $\sim 8 \%$ for FTAZ:ITIC is similar to those obtained when the donor polymer FTAZ was paired with other high-performing, non-fluorinated ITIC derivatives. ${ }^{12,15}$

Table 1 Photovoltaic characteristics of FTAZ:ITIC- and HTAZ:ITICbased solar cells

\begin{tabular}{llcll}
\hline Blend & $V_{\text {oc }}(\mathrm{V})$ & $J_{\text {sc }}\left(\mathrm{mA} \mathrm{cm}^{-2}\right)$ & FF $(\%)$ & PCE $(\%)$ \\
\hline FTAZ:ITIC & $0.911 \pm 0.001$ & $16.25 \pm 0.46$ & $56.5 \pm 1.5$ & $8.37 \pm 0.40$ \\
HTAZ:ITIC & $0.851 \pm 0.001$ & $12.54 \pm 0.49$ & $39.9 \pm 0.9$ & $4.26 \pm 0.24$
\end{tabular}
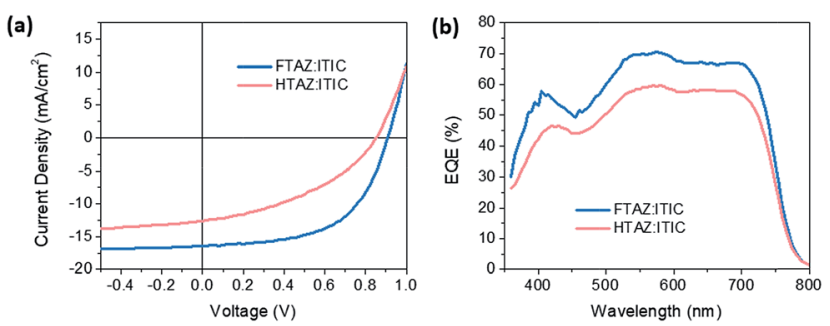

Fig. 2 (a) Representative $J-V$ curves and (b) EQE spectra of FTAZ:ITIC- and HTAZ:ITIC-based BHJ devices. 
In addition to the $J-V$ characteristics, the external quantum efficiency (EQE) of the devices was measured. As shown in Fig. 2b, both FTAZ:ITIC and HTAZ:ITIC display a broad EQE response with contributions from both the donor and acceptor; however, FTAZ:ITIC has a higher response across the entire spectrum, reaching a maximum of $\sim 70 \%$ compared to only $\sim 60 \%$ for HTAZ:ITIC. This increase in EQE for FTAZ:ITIC is consistent with the improved $J_{\text {sc }}$ observed in the FTAZ-based device.

\section{Device physics}

To further understand the effect of donor polymer fluorination in these devices, we first investigated the cause of the large $J_{\mathrm{sc}}$ increase in the FTAZ:ITIC device. We chose to focus on the increase in $J_{\mathrm{sc}}$ first rather than the similarly large increase in $\mathrm{FF}$, because the $J_{\text {sc }}$ improvement was not previously observed in PCBM-based devices with HTAZ and FTAZ. In order to understand this enhancement in $J_{\mathrm{sc}}$, we needed to consider the various processes involved in current generation in PSCs. To generate current, an exciton needs to first be formed and subsequently dissociated into free charge carriers at the donoracceptor (D-A) interface. Then, these free charge carriers need to be transported through the device and extracted at the electrodes before recombination occurs.

We first studied the exciton dissociation by measuring the photoluminescence (PL) quenching in these blends (Fig. 3). As shown in Fig. 3a, ITIC is able to quench the PL of both FTAZ and HTAZ nearly completely, with a similar quenching efficiency of $\sim 99 \%$ for both blends. Similarly, both polymers are able to efficiently quench the PL of ITIC, as displayed in Fig. 3b. The high PL quenching efficiency for all materials suggests efficient exciton dissociation in both the FTAZ- and HTAZ-based devices, likely due to a morphology with small and/or mixed enough domains.

We then considered the recombination mechanisms occurring in the devices, as recombination will compete with charge extraction and lower the current generation. To gain insight into the recombination mechanisms in the FTAZ:ITIC- and HTAZ:ITIC-based devices, we measured the light intensity dependence of both $J_{\mathrm{sc}}$ and $V_{\mathrm{oc}}$ (Fig. 4). $J_{\mathrm{sc}}$ is known to have a power law dependence on light intensity, and the slope of the $J_{\text {sc }} v s$. intensity $\log$ plot will equal one if there is minimal bimolecular recombination in the device. ${ }^{27}$ From the log-log plot of $J_{\mathrm{sc}} v s$. light intensity shown in Fig. $4 \mathrm{a}$, it is clear that the
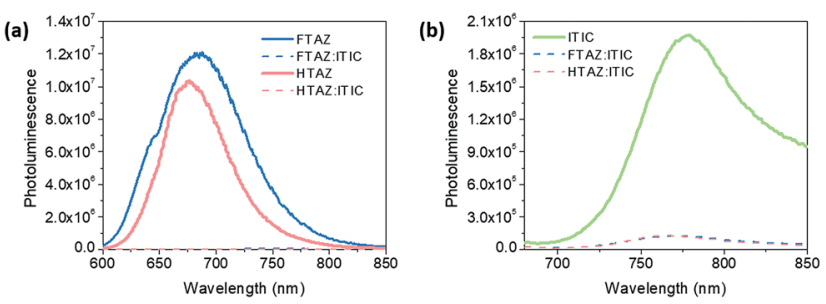

Fig. 3 Photoluminescence of (a) neat FTAZ and HTAZ (excitation at $530 \mathrm{~nm}$ ) and (b) neat ITIC (excitation at $650 \mathrm{~nm}$ ) films and both $\mathrm{BHJ}$ blend films.
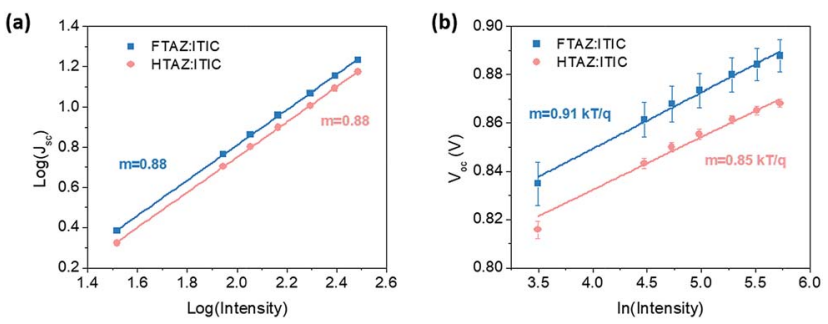

Fig. 4 Light intensity dependence of (a) $J_{\mathrm{sc}}$ and (b) $V_{\mathrm{oc}}$ for the FTAZ:ITIC- and HTAZ:ITIC-based devices.

FTAZ:ITIC and HTAZ:ITIC devices have the same slope, indicating a similar degree of bimolecular recombination in these devices at short circuit condition. The slope for both the FTAZand HTAZ-based device is 0.88 , which signifies there is a small amount of bimolecular recombination for both devices. In a previous study, ${ }^{28}$ the light intensity dependence of the FTAZ:PCBM-based device was also studied. The slope of the loglog plot was determined to be 0.93 , indicating a slightly lower degree of bimolecular recombination in the PCBM-based device than the ITIC-based device studied here.

The $V_{\text {oc }}$ dependence on light intensity is displayed in Fig. $4 \mathrm{~b}$. When bimolecular recombination is the sole loss mechanism, a plot of $V_{\mathrm{oc}} v s$. the natural log of light intensity will have a slope equal to $k T / q .{ }^{27}$ Similar to $J_{\mathrm{sc}}$, the $V_{\mathrm{oc}}$ dependence on light intensity shows comparable slopes for both the FTAZ- and HTAZ-based device, with a slope of $0.91 \mathrm{kT} / \mathrm{q}$ and $0.85 \mathrm{kT} / \mathrm{q}$ for FTAZ:ITIC and HTAZ:ITIC, respectively. This again indicates a similar degree of recombination in these devices, which decreases the overall current generation for both blends. Additionally, these values suggest that bimolecular recombination is the dominant mechanism in these devices as opposed to monomolecular, as monomolecular recombination will lead to a slope of $2 \mathrm{kT} / \mathrm{q}$ in the $V_{\mathrm{oc}} v s$. intensity plot. ${ }^{29}$ The results obtained from the light intensity study are similar to those obtained by Li et al. in their earlier study, ${ }^{7}$ where they found that all devices had nearly identical bimolecular recombination coefficients, regardless of fluorination amount. Here, we demonstrate that replacing PCBM with ITIC as the acceptor again leads to a comparable degree of recombination in both the fluorinated (FTAZ) and non-fluorinated (HTAZ) polymer.

After exciton dissociation, the newly generated free charge carriers need to be transported through the device and extracted at the electrodes to generate current. To study the charge transport in these solar cells, we first measured the charge mobility via the space charge limited current (SCLC) method. The electron and hole mobility values are given in Table 2 . The device based on fluorinated FTAZ displays a higher electron and hole mobility than that of the device based on non-fluorinated HTAZ. This higher charge mobility would lead to improved charge transport in the FTAZ:ITIC-based device, contributing to the improvement in $J_{\mathrm{sc}}$ and also in FF. Although the FTAZ:ITICbased device has higher mobility values than that of the HTAZ:ITIC-based device, the mobility observed in both blends is still low, on the order of only $10^{-5} \mathrm{~cm}^{2} \mathrm{~V}^{-1} \mathrm{~s}^{-1}$ for hole mobility and $10^{-6}$ for electron mobility. These low mobility 
Table 2 Electron and hole mobility values for the FTAZ:ITIC- and HTAZ:ITIC-based devices

\begin{tabular}{lll}
\hline Blend & $\begin{array}{l}\text { Hole mobility } \\
\left(\times 10^{-5} \mathrm{~cm}^{2} \mathrm{~V}^{-1} \mathrm{~s}^{-1}\right)\end{array}$ & $\begin{array}{l}\text { Electron mobility } \\
\left(\times 10^{-5} \mathrm{~cm}^{2} \mathrm{~V}^{-1} \mathrm{~s}^{-1}\right)\end{array}$ \\
\hline FTAZ:ITIC & $9.3 \pm 1.4$ & $0.59 \pm 0.17$ \\
HTAZ:ITIC & $1.9 \pm 0.6$ & $0.15 \pm 0.06$
\end{tabular}

values, along with the imbalance in the hole and electron mobility, could be a contributing factor to the lower fill factors observed in these devices, due to the potential for a build-up of space charge that would increase the bimolecular recombination and be detrimental to charge transport. ${ }^{30}$

To further understand the charge transport and extraction in these PSCs, we measured the photocurrent and charge collection probability (Fig. 5). The photocurrent $\left(J_{\mathrm{ph}}\right)$ is calculated by subtracting the dark current density $\left(J_{\mathrm{D}}\right)$ from the current density under illumination $\left(J_{\mathrm{L}}\right)$. This value can then be plotted against the effective voltage, $V_{\text {eff }}$, which is found by subtracting the applied voltage $(V)$ from the compensation voltage $\left(V_{0}\right)$ at which $J_{\mathrm{ph}}$ is equal to zero. ${ }^{31}$ The plot of $J_{\mathrm{ph}} v s$. $V_{\text {eff }}$ gives insight to the saturated photocurrent, $J_{\mathrm{ph}, \mathrm{sat}}$, which is the point at which all free carriers are extracted to the electrodes with minimal recombination. The saturated photocurrent is independent of the electric field, and affected by both field-independent losses and the optical absorption of the film. ${ }^{32}$ Fig. 5a demonstrates that the FTAZ:ITIC-base device has a higher $J_{\mathrm{ph} \text {,sat }}$ than that of the HTAZ:ITIC-based device, which agrees with the higher $J_{\mathrm{sc}}$ of this device. This increase in photocurrent could be due in part to the higher absorption of the FTAZ-based blend compared to that of the HTAZ-based one (Fig. S2 $\dagger$ ). Additionally, by normalizing the photocurrent with respect to $J_{\mathrm{ph} \text {,sat }}$, we are able to calculate the charge collection probability $\left(P_{c}\right)$ of the devices (Fig. 5b). ${ }^{32}$ The FTAZ:ITIC-based device displays a higher $P_{\mathrm{c}}$ than that of the HTAZ:ITIC-based one, indicating more efficient charge extraction in the FTAZ-based device, which would lead to a higher current compared to the HTAZ-based device.

\section{Morphology}

We also studied the morphology of the $\mathrm{BHJ}$ blend films, as morphology can have a large effect on photovoltaic properties. Grazing incidence wide angle X-ray scattering (GIWAXS) was used to determine the molecular packing within the film. As
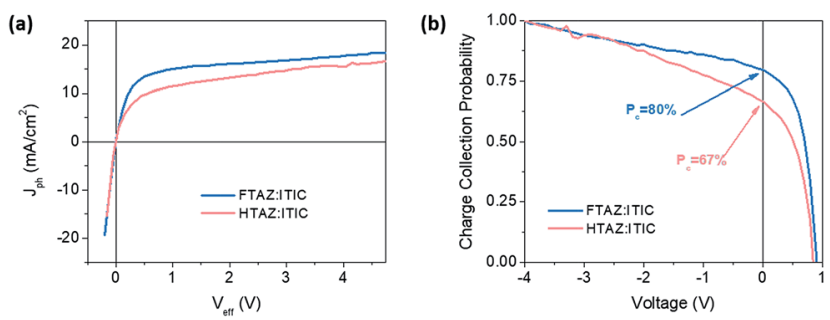

Fig. 5 (a) Photocurrent and (b) charge collection probability of the FTAZ:ITIC- and HTAZ:ITIC-based devices. (a)

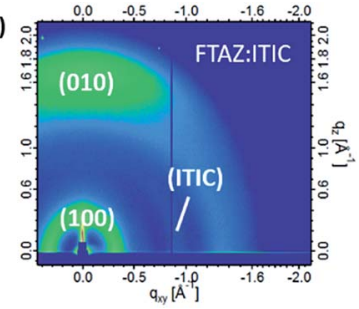

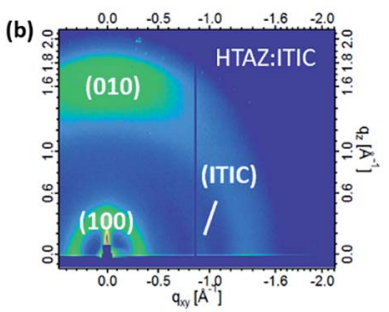

Fig. 6 2D GIWAXS patterns for (a) FTAZ:ITIC and (b) HTAZ:ITIC films.

Table 3 Domain spacing and relative purity for FTAZ:ITIC and HTAZ:ITIC blends from RSoXS data

\begin{tabular}{lll}
\hline Blend & $\begin{array}{l}\text { Domain spacing } \\
(\mathrm{nm})\end{array}$ & $\begin{array}{l}\text { Relative composition } \\
\text { variations }\end{array}$ \\
\hline FTAZ:ITIC & 50.2 & 1 \\
HTAZ:ITIC & 59.8 & 0.9 \\
\hline
\end{tabular}

displayed in the 2D GIWAXS patterns for these blend films (Fig. 6), both the FTAZ:ITIC blend film and the HTAZ:ITIC blend film display similar, mostly amorphous packing. The disorder in these films could play a large role in the low charge mobility values discussed previously. It is possible that improving the crystallinity in these blends would lead to improved charge transport and further increase the performance for these polymer systems. In addition to the GIWAXS data, resonant soft Xray scattering (RSoXS) was utilized to measure the domain spacing and relative composition variations of the $\mathrm{BHJ}$ films. The RSoXS data have been corrected using the Lorentz correction (Fig. S6†) with the assumption of a globally isotropic 3dimensional morphology and that long periods of Lorentzcorrected profiles give a good agreement to real-space domain spacing, which has already been justified. ${ }^{33,34}$ The relative composition variations, related to domain purities, are 1 and 0.9 for FTAZ:ITIC and HTAZ:ITIC, respectively (Table 3). The more pure domains for the FTAZ:ITIC blend trends with the higher FF observed for its device, as impure domains can lead to increased bimolecular recombination and reduce the FF. Additionally, the FTAZ:ITIC blend has a smaller domain spacing of $50 \mathrm{~nm}$ compared to $60 \mathrm{~nm}$ for the HTAZ:ITIC one, which is beneficial for charge transport and agrees with the higher $J_{\mathrm{sc}}$ for the FTAZ:ITIC-based photovoltaic device.

\section{Conclusions}

In summary, with FTAZ/HTAZ as the exemplary conjugated polymers, we show that fluorination of the donor polymer also leads to much improved device performance in solar cells with ITIC as the non-fullerene acceptor, similar to our previous discovery of fluorination-induced-efficiency enhancement in fullerene (e.g., PCBM)-based devices. The observed increase in $V_{\text {oc }}$ with fluorination - in both PCBM-based devices and ITICbased ones - can be ascribed to the lower HOMO level of the fluorinated FTAZ compared to its non-fluorinated counterpart 
HTAZ. Furthermore, the increase of FF by $40 \%$ from HTAZ to FTAZ in their ITIC-based devices - also similar to the FF enhancement observed in their PCBM-based devices - can be largely explained by the increased hole mobility with fluorination, as well as the increase in electron mobility. However, a large improvement of $30 \%$ was observed for the $J_{\text {sc }}$, which was not seen in previous studies of these two polymers in their PCBM-based BHJ solar cells. By studying the various processes involved in current generation in PSCs, we determined that the increase in $J_{\mathrm{sc}}$ for the ITIC-based devices is due to improved charge transport and extraction in the FTAZ:ITIC-based device compared to HTAZ:ITIC-based one, stemming from the higher electron and hole mobility, as well as a higher saturated photocurrent and charge collection probability for the FTAZ:ITIC-based device.

The results of this study demonstrate that donor polymer fluorination is also a viable method to further increase efficiency in NFA-based PSCs, and may improve performance through different mechanisms than those observed in fullerene-based PSCs. To fully understand the "F effect" in NFAbased solar cells, further study is required utilizing other efficient, fluorinated donor polymers, such as those recently reported by Zhang et al. ${ }^{35}$ Additionally, there have been a few reports demonstrating that fluorination of the non-fullerene acceptor leads to improved device performance, ${ }^{15,24}$ which should also be considered in future studies of the "F effect."

\section{Experimental}

\section{Device fabrication}

Solar cells were fabricated on glass substrates with patterned indium doped tin oxide (ITO). ITO substrates were cleaned via sonication in deionized water, acetone and isopropyl alcohol for fifteen minutes each, followed by UV-ozone treatment for 15 minutes. The $\mathrm{ZnO}$ precursor solution was prepared by dissolving $1 \mathrm{~g}$ zinc acetate dihydrate and $0.28 \mathrm{~g}$ ethanolamine in $10 \mathrm{~mL}$ of 2-methoxyethanol. The solution was stirred overnight, and then spun cast onto the cleaned ITO at $6000 \mathrm{rpm}$ for $60 \mathrm{~s}$, then baked at $200{ }^{\circ} \mathrm{C}$ for 30 minutes in air. The substrates were then transferred into a nitrogen filled glovebox. Polymer:ITIC solutions (D : A $=1: 1.5,6 \mathrm{mg} \mathrm{mL} \mathrm{m}^{-1}$ polymer) in chloroform were prepared for both polymers and spun cast at $5000 \mathrm{rpm}$ for $60 \mathrm{~s}$. The solar cells were finished by evaporation of $10 \mathrm{~nm} \mathrm{MoO}_{3}$ and $50 \mathrm{~nm}$ of aluminum, with a device area of $13 \mathrm{~mm}^{2}$, and tested under AM 1.5G irradiation calibrated with an NREL certified standard silicon solar cell. Current density-voltage curves were measured via a Keithley 2400 digital source meter.

\section{SCLC measurements}

Electron and hole mobilities were measured via the spacecharge limited current (SCLC) method. Electron-only devices were fabricated with the configuration ITO/ZnO/Polymer:ITIC/ $\mathrm{Ca} / \mathrm{Al}$, and hole-only devices were also prepared with the configuration ITO/PEDOT:PSS/Polymer:ITIC/ $\mathrm{MoO}_{3} / \mathrm{Al}$. The dark current densities were measured with an applied voltage from 0 to $6 \mathrm{~V}$ using a Keithley 2400 digital source meter. The applied voltage was corrected from the voltage drop due to series and contact resistance. The Mott-Gurneys law was utilized to extract mobility values:

$$
J=\frac{9}{8} \varepsilon_{r} \varepsilon_{0} \mu_{\mathrm{h}} \frac{V^{2}}{L^{3}}
$$

where $\varepsilon_{\mathrm{r}}$ is the dielectric constant of the tetramer, $\varepsilon_{0}$ is the permittivity of free space, $\mu_{\mathrm{h}}$ is the hole mobility, $V$ is the voltage drop across the device, and $L$ is the thickness of the active layer.

\section{Morphology}

GIWAXS, R-SoXS and NEXAFS reference spectra measurements were respectively performed at the beamline 7.3.3 (ref. 36) and beamline 11.0.1.2, ${ }^{37}$ beamline 5.3.2.2, ${ }^{38}$ Advanced Light Source (ALS), Lawrence Berkeley National Laboratory, following the previously established protocols. GIWAXS data were acquired just above the critical angle $\left(0.13^{\circ}\right)$ of the films with a hard X-ray energy of $10 \mathrm{keV}$, and Silver Behenate (AgB) was used for geometry calibration. R-SoXS was performed in a transmission geometry with linearly polarized photons under high vacuum (1 $\times 10^{-7}$ torr) and a cooled $\left(-45^{\circ} \mathrm{C}\right) \mathrm{CCD}$ (Princeton PI-MTE, 2048 pixels $\times 2048$ pixels) was used to capture the soft X-ray scattering 2D maps and PS300 was used for geometry calibration. The raw 2D X-ray data was processed with a modified version of NIKA into 1D scattering profiles $I(q))^{39}$

\section{Conflicts of interest}

There are no conflicts to declare.

\section{Acknowledgements}

N. B., Q. Z., and W. Y. were supported by the Office of Naval Research (Grant No. N000141410221), and a NSF grant (DMR1507249). W. Y. and L. Y. were supported by a NSF grant (CBET1639429). Work by NCSU was supported by ONR grant N00141512322. X-ray data was acquired at beamlines 11.0.1.2, and 7.3.3 at the Advanced Light Source, which is supported by the Director, Office of Science, Office of Basic Energy Sciences, of the U.S. Department of Energy under Contract No. DE-AC0205CH11231. A. L. D. Kilcoyne, E. Schaible, A. Hexemer, and C. Wang, of the ALS (DOE) assisted with the measurements and/or provided instrument maintenance. We also thank Wesley Swords and Professor Gerald Meyer (University of North Carolina at Chapel Hill) for assistance with PL measurements.

\section{Notes and references}

1 Q. Zhang, M. A. Kelly, N. Bauer and W. You, Acc. Chem. Res., 2017, 50(9), 2401-2409.

2 N. Leclerc, P. Chávez, O. Ibraikulov, T. Heiser and P. Lévêque, Polymers, 2016, 8(1), 11.

3 X.-P. Xu, Y. Li, M.-M. Luo and Q. Peng, Chin. Chem. Lett., 2016, 27(8), 1241-1249.

4 F. Meyer, Prog. Polym. Sci., 2015, 47, 70-91.

5 S. C. Price, A. C. Stuart, L. G. Yang, H. X. Zhou and W. You, J. Am. Chem. Soc., 2011, 133(12), 4625-4631. 
6 W. Li, L. Yang, J. R. Tumbleston, L. Yan, H. Ade and W. You, Adv. Mater., 2014, 26(26), 4456-4462.

7 W. Li, S. Albrecht, L. Yang, S. Roland, J. R. Tumbleston, T. McAfee, L. Yan, M. A. Kelly, H. Ade, D. Neher and W. You, J. Am. Chem. Soc., 2014, 136(44), 15566-15576.

8 Y. Lin and X. Zhan, Adv. Energy Mater., 2015, 5(20), 1501063.

9 C. B. Nielsen, S. Holliday, H. Chen, S. J. Cryer and I. Mcculloch, Acc. Chem. Res., 2015, 48(11), 2803-2812.

10 Y. Lin and X. Zhan, Acc. Chem. Res., 2016, 49(2), 175-183.

11 Y. Lin, J. Wang, Z. Zhang, H. Bai, Y. Li, D. Zhu and X. Zhan, Adv. Mater., 2015, 27(7), 1170-1174.

12 S. Dai, F. Zhao, Q. Zhang, T.-K. Lau, T. Li, K. Liu, Q. Ling, C. Wang, X. Lu, W. You and X. Zhan, J. Am. Chem. Soc., 2017, 139(3), 1336-1343.

13 Y. Lin, F. Zhao, Q. He, L. Huo, Y. Wu, T. C. Parker, W. Ma, Y. Sun, C. Wang, D. Zhu, A. J. Heeger, S. R. Marder and X. Zhan, J. Am. Chem. Soc., 2016, 138(14), 4955-4961.

14 S. Li, L. Ye, W. Zhao, S. Zhang, S. Mukherjee, H. Ade and J. Hou, Adv. Mater., 2016, 28(42), 9423-9429.

15 F. Zhao, S. Dai, Y. Wu, Q. Zhang, J. Wang, L. Jiang, Q. Ling, Z. Wei, W. Ma, W. You, C. Wang and X. Zhan, Adv. Mater., 2017, 29(18), 1700144.

16 J. Wang, W. Wang, X. Wang, Y. Wu, Q. Zhang, C. Yan, W. Ma, W. You and X. Zhan, Adv. Mater., 2017, 29(35), 1702125.

17 H. Yao, L. Ye, J. Hou, B. Jang, G. Han, Y. Cui, G. M. Su, C. Wang, B. Gao, R. Yu, H. Zhang, Y. Yi, H. Y. Woo, H. Ade and J. Hou, Adv. Mater., 2017, 29(21), 1700254.

18 Y.-Q.-Q. Yi, H. Feng, M. Chang, H. Zhang, X. Wan, C. Li, Y. Chen, H. Zhang, C. Li, J. Hou, Y. Chen, S. R. Marder, X. Zhan, A. Amassian, A. Salleo, T. Kirchartz, J. R. Durrant and I. McCulloch, J. Mater. Chem. A, 2017, 5(33), 1720417210.

19 B. Guo, W. Li, X. Guo, X. Meng, W. Ma, M. Zhang and Y. Li, Adv. Mater., 2017, 29(36), 1702291.

20 F. Lin, W. Huang, H. Sun, J. Xin, H. Zeng, T. Yang, M. Li, X. Zhang, W. Ma and Y. Liang, Chem. Mater., 2017, 29(13), 5636-5645.

21 W. Wang, C. Yan, T.-K. Lau, J. Wang, K. Liu, Y. Fan, X. Lu and X. Zhan, Adv. Mater., 2017, 29(31), 1701308.

22 X. Bao, Y. Zhang, J. Wang, D. Zhu, C. Yang, Y. Li, C. Yang, J. Xu and R. Yang, Chem. Mater., 2017, 29(16), 6766-6771.

23 T. Yu, X. Xu, G. Zhang, J. Wan, Y. Li and Q. Peng, Adv. Funct. Mater., 2017, 27(28), 1701491.
24 W. Zhao, S. Li, H. Yao, S. Zhang, Y. Zhang, B. Yang and J. Hou, J. Am. Chem. Soc., 2017, 139(21), 7148-7151.

25 Z. Li, K. Jiang, G. Yang, J. Y. L. Lai, T. Ma, J. Zhao, W. Ma and H. Yan, Nat. Commun., 2016, 7, 13094.

26 L. Gao, Z. Zhang, H. Bin, L. Xue, Y. Yang, C. Wang, F. Liu, T. P. Russell and Y. Li, Adv. Mater., 2016, 28(37), 8288-8295.

27 A. K. K. Kyaw, D. H. Wang, V. Gupta, W. L. Leong, L. Ke, G. C. Bazan and A. J. Heeger, ACS Nano, 2013, 7(5), 45694577.

28 N. Bauer, Q. Zhang, J. Zhao, L. Ye, J.-H. Kim, I. Constantinou, L. Yan, F. So, H. Ade, H. Yan and W. You, J. Mater. Chem. A, 2017, 5(10), 4886-4893.

29 S. R. Cowan, A. Roy and A. J. Heeger, Phys. Rev. B: Condens. Matter Mater. Phys., 2010, 82(24), 245207.

30 C. M. Proctor, J. A. Love and T.-Q. Nguyen, Adv. Mater., 2014, 26(34), 5957-5961.

31 P. W. M. Blom, V. D. Mihailetchi, L. J. A. Koster and D. E. Markov, Adv. Mater., 2007, 19(12), 1551-1566.

32 L. Yang, J. Tumbleston, H. Zhou, H. Ade and W. You, Energy Environ. Sci., 2013, 6, 316-326.

33 L. Ye, Y. Xiong, S. Li, M. Ghasemi, N. Balar, J. Turner, A. Gadisa, J. Hou, B. T. O'Connor and H. Ade, Adv. Funct. Mater., 2017, 27(33), 1702016.

34 S. Mukherjee, A. Herzing, D. Zhao, Q. Wu, L. Yu, H. Ade, D. M. DeLongchamp and L. J. Richter, J. Mater. Res., 2017, 32(10), 1921-1934.

35 Q. Zhang, L. Yan, X. Jiao, Z. Peng, S. Liu, J. J. Rech, E. Klump, H. Ade, F. So and W. You, Chem. Mater., 2017, 29(14), 59906002.

36 A. Hexemer, W. Bras, J. Gossinger, E. Schaible, E. Gann,

R. Kirian, A. MacDowell, M. Church, B. Rude and

H. Padmore, J. Phys.: Conf. Ser., 2010, 247(1), 12007.

37 E. Gann, A. T. Young, B. A. Collins, H. Yan, J. Nasiatka, H. A. Padmore, H. Ade, A. Hexemer and C. Wang, Rev. Sci. Instrum., 2012, 83(4), 45110.

38 A. L. D. Kilcoyne, T. Tyliszczak, W. F. Steele, S. Fakra, P. Hitchcock, K. Franck, E. Anderson, B. Harteneck, E. G. Rightor, G. E. Mitchell, A. P. Hitchcock, L. Yang, T. Warwick and H. Ade, J. Synchrotron Radiat., 2003, 10, 125-136.

39 J. Ilavsky, J. Appl. Crystallogr., 2012, 45(2), 324-328. 